\section{A Performative Threshold Between Teaching Research and Practice Atlas Poliphilo as Scaffold}

\section{Dieter Dietz}

ALICE, Swiss Federal Institute of Technology of Lausanne

\section{Aurélie Dupuis}

ALICE, Swiss Federal Institute of Technology of Lausanne

Julien Lafontaine Carboni

ALICE, Swiss Federal Institute of Technology of Lausanne

\section{Dario Negueruela del Castillo}

ALICE, Swiss Federal Institute of Technology of Lausanne
Hunches allow us to navigate in a trans-scalar world. Without them, teachers, researchers and practitioners would be left aimless. Hunches relate to the embodied and synthetic nature of the knowledge we produce, but also to its unfolding. Instead of denying importance of hunches or minimizing their impact, can we imagine to build a more apt framework for the kinds of encounters and negotiation they facilitate? Shall we do it within pre-existing academic and practical knowledge? Can we set up a pedagogical experience that sets a time and space to collectively integrate and share hunches, to experiment with them and to ultimately operationalize them in designerly or scientific manners?

In this paper, we introduce and discuss our experience with Atlas Poliphilo, an experimental studio that runs its second iteration during the spring semester 2019. Neither a design studio nor a seminar, the Atlas sets up a framework for collaborative enquiry that further elaborates on them. The course gathers students from civil and environmental engineering together with students of architecture, and landscape architecture to work collaboratively for one semester. This experience is framed in our work on new visions for the trans-border Greater Geneva as one of the selected teams aiming at tackling its current social, economic and environmental challenges and constructing a framework to think and discuss its growth in the next 35 years.

This interdisciplinary course addresses an alternative of perceiving and integrating the constitutive complexity of the territory and the intertwined trajectories of all its different agents. Departing from the situated experiences of the students within a given site of exploration, the course aims at carefully unfolding their many dimensions - the relational and performative aspects of involvement, bodily experience, environmental context and objects, individual and collective cultural frames - allowing to experiment with them and to render them explicit. This is grounded on the conviction that an ability to affect is reciprocated by a capacity of being affected.

\section{SKETCH AND PROBLEMATIZATION OF THE ACTIVITIES OF THE ATLAS}

The course Atlas Poliphilo is structured around a specific kind of territorial survey. Each two weeks, the students stroll through the territory of Greater Geneva, trying to follow its infrastructural networks as they manifest into space, through the technical emergences or big voids in the city fabric. These spaces are neither integrated in our daily practice of the territory, nor are they in our minds and images of the city. Yet they are of great influence for the future of the territory, situated for most of them in a shared industrial-agricultural belt between Switzerland and France The course is based on the idea that discussing and thinking further territorial strategies could not happen without getting to know the concerned territory, as it affects us. Space is hypothesized as a common support for individual and collective articulation of interactions.

Sharing these affects and structuring our further territorial 


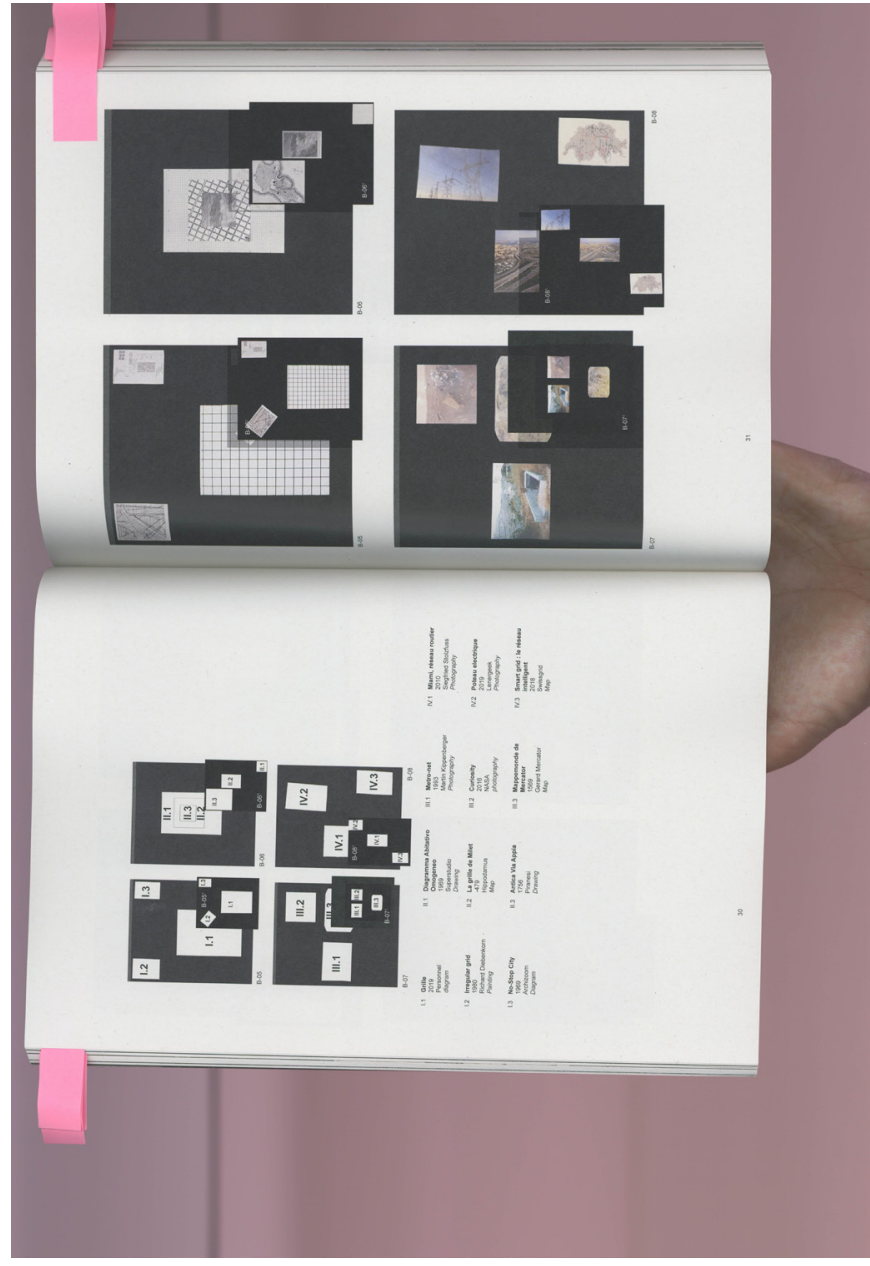

Figure 1. Boards B_05,B_06,B_07,B_08 of the Atlas Poliphilo 2019. These boards ermerged as reference boards, both to encounter the medium and the topic of infrastructural networks.

exploration collectively in relation to them is the first aim of the courses taking place at EPFL. This process is articulated through the iterative use and thematic composition of boards. This approach dwells on the method devised by Aby Warburg for the elaboration of his renown Atlas Mnemosyne ${ }^{1}$. The Atlas is composed of a blackboard series on which reproductions of paintings, sculptures, maps, drawings, diagrams or photography, are laid. This arrangement allows for unveiling complex relationships among art works across different times and eras. On the boards, the relative location of images with respect to the other images articulates relations of influence, similarity or variation according to several layers of analysis (see figure 1). On similar black boards, participants reconstitute the territory of Greater Geneva through the disposition and arrangement of different data and images, with the aim to re-enact the territory through an operational analogy. This emerging figuration of the territory is both situated and embodied, letting the geographical, the experienced and the mental geography influence each other through the inner structure of the boards and the collective constellation they constitute together. It unfolds through our common affect, considered as

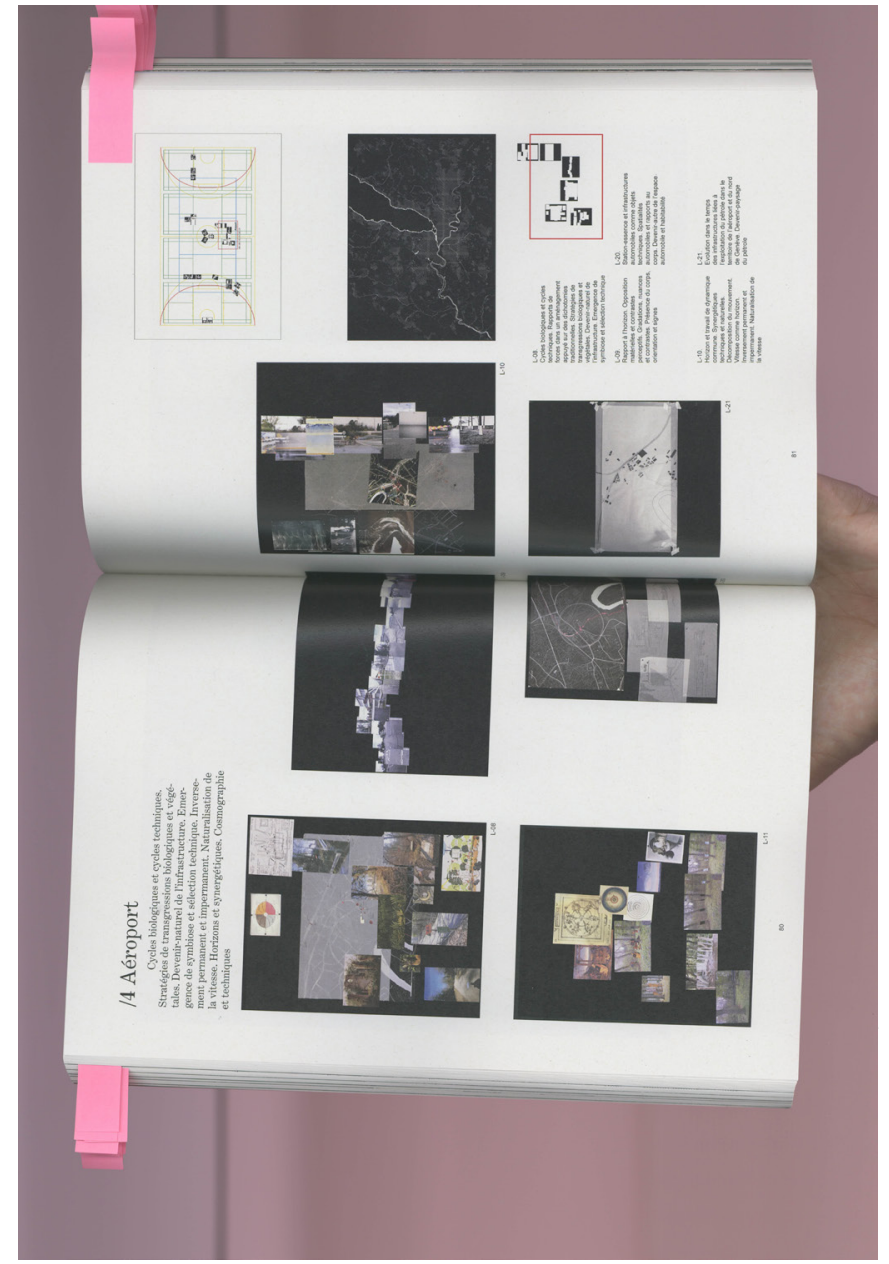

Figure 2. Cluster of Boards_04. Boards L_06, L_09, L_10, L_11, L_20, L_21. These boards were manufactured within the frame of the second restitution in the gymnasium.

enrich each other.

The second series is constituted as a geographically situated path through the territory. However, the narration is done only through images of reference, which allow for beginning to inscribe and think the historically situated and constituted nature of our embodied knowledge. Similarly to the boards of Warburg, where everyday objects are considered in parallel with art masterpieces, different images and cognitive relationships take place on the boards. Figures start to appear through time and space that were not before associated. This intertwining of history with our own affective memories, of the visible and the invisible, allows for very particular narratives to unfold and directly question the fixed and flattened image we have of this specific territory. It moreover reveals in parallel the capacity of our bodies to feel and act in the territory in a very broad range of manners.

The emerging figuration on the boards is soon "walked through", shared and discussed. All of them compose a collective constellation installed on the floor of a gymnasium (figure $2 \& 3$ ). It is a moment of 
synthesis, of letting us be caught by the different narrative threads, making places out of these panels. We collectively noticed at that time that no universal model exists to describe and understand what we are looking at. Nevertheless we discovered a strong common dimension of our affective condition in unfolding the space we share. This experience begins to make the virtual aspect of our relation to space felt again. Alternative paths open from within our common embodied experience.

The atlas of boards now operates as cognitive support. As thick threshold offering critical distance and asking for engagement at the same time, it makes us capable of thinking and acting anew in the territory. This takes the form of a collective action, performed and watched by the participants directly in the territory. The group is carrying outside the university what was shared within it. We experience the agency of the atlas as a model on the reality and the deepness of our actions, being supported and amplified by the constellation as common affect. By walking and reacting to what we perceive, we imbricate to this wandering fragments of our discussions, of our dreams, of our thoughts, narrated by voices or bodies of participants. These micro-actions reinforce the connection with the atlas and the making tangible of the virtual.

The last weeks are dedicated to an unfolding of the atlas' agential capacities through diverse mediums in order to try to share it with non-participants. Here, we confront the fact that this shared experience stays quite opaque to newcomers as the new knowledge is situated between ourselves, the boards and the territory. Instead of trying to make them fully enter in the complexity of the model, we chose to unveil the operative capacity of the atlas. The participants therefore imagined new paths to be followed by anyone, informed with layers of speed and time, stories from the past or a future, gestures to perform, things to look at, spaces to occupy. These were presented and discussed through geographic description of the path, audiotape, atlas boards and written scenario of the performance. If all of the atlas's richness cannot be shared instantly, it is a device capable of enhancing our capacities to tell new stories, amplifying the life and experience of those who engage with it to diverse degrees and unfold its matter.

\section{WHEN THE SCAFFOLD BECOMES AN ENVIRONMENT}

A crucial departing point for the development of the course was the extent to which the different elements of the Atlas would contribute significantly to make it a cognitive scaffolding. In rethinking the role of external devices to enhance our cognitive and affective capacities within an educational and professional framework, we question the Atlas through Sterelny's dimensions, like the establishment of trust, or the capacity to be seamlessly incorporated or entrenched ${ }^{2}$. During the course, participants compose and re-compose boards, adding and correcting associations, concepts, references in every iteration. Through the collective practice, participants slowly learn to use the boards not as simple background for the display of some references, but as to effectively incorporate them in their thinking dialogic. The

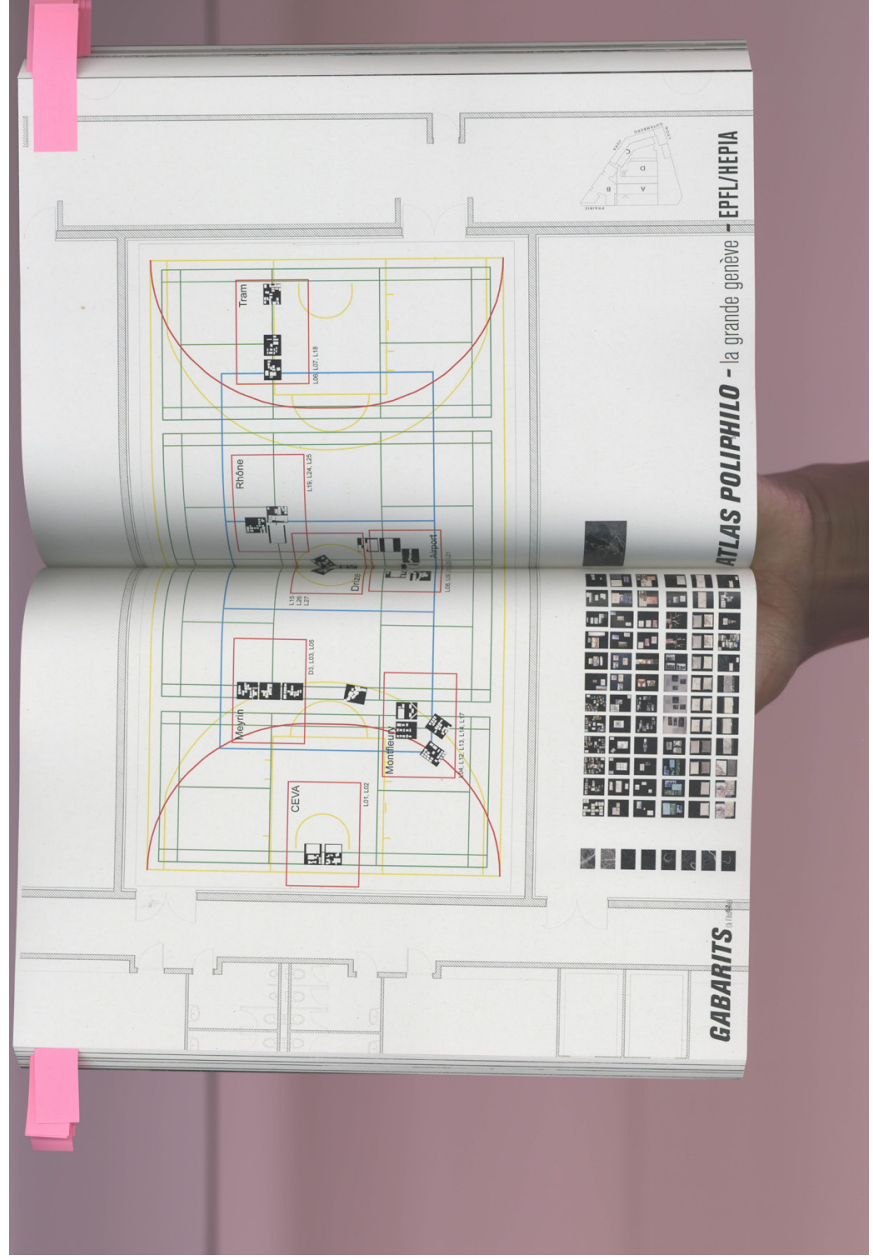

Figure 3. Plan of the Gymnasium prepared for the restitution, figuring the clusters of boards, and their spatial and territorial relationships.

boards, so to speak, become transparent and full of content and intention, like true constituent elements of a cognitive process. This process, however, takes considerable time and practice, rendering thee method at times impermeable to externals.

Here, one of the questions most relevant to the discussion on the relationship teaching/practice is how the articulation of these cognitive aids together with a welcoming and open structure where a constant collective renegotiation of the tools takes place, contributes to their "upgrade" to become what could be termed as an environment proper. Within current literature on cognitive and learning aids ${ }^{3}$, the objectual entity of such aids remains stable throughout the learning process $^{4}$. Only perhaps in considerations of the social body in its role as learning aid $^{5}$, there are glimpses on the transformations that the active engagement in the learning process imposes on some of its constituent elements. In contrast, in the case of the Atlas the elements, ingredients, tools, contents as well as participants themselves are incorporated as fully capable or "agential" actors, aiming at granting them a place and a voice. This turns them, as it were, into active 


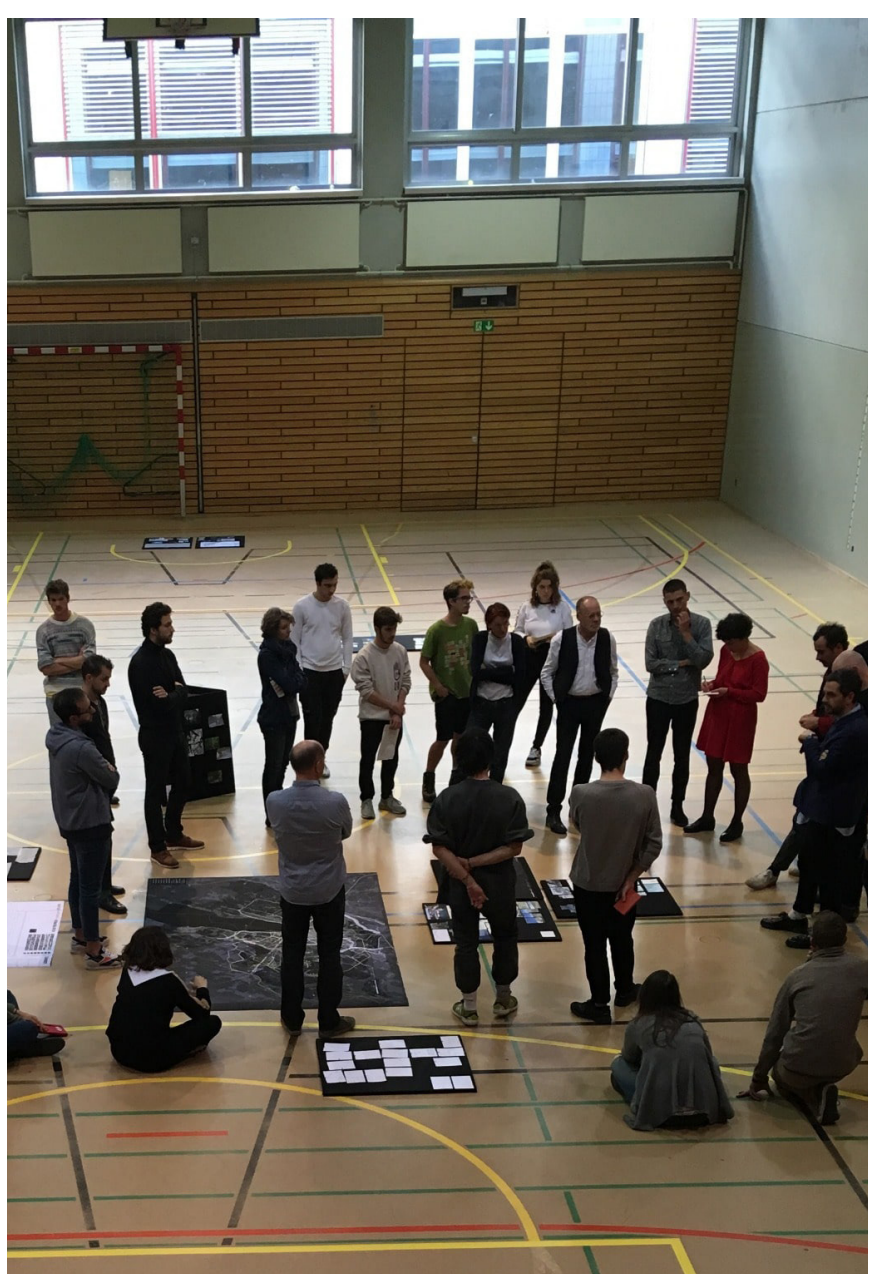

Figure 4. Second Restitution of the Atlas Poliphilo course in the Sports hall in Geneva.

participants. As such, the entities involved in the course are subject to constant re-interpretation, re negotiation and re-constitution. The intermediary crit of the course took place in a university Sports hall in Geneva (figure 4). Boards were displayed in a collectively conceived composition intended at facilitating and furthering conversation. It became clear that the spatial dimension was indeed performative in modulating precisely the vicinity and reachability of specific compositions, actively influencing the unfolding of the crits. Here again we perceived that such a mise en espace could not be read and engaged with equally by those who had just arrived to our Atlas, reminding us of the barriers that might arise with such decanted and involvement-demanding methods of learning.

This is perhaps one of the most ambitious and speculative contributions of the Atlas: that of turning usual scheme of the learning and cognitive aids inside out. Tools, references, ingredients are no longer objects one reaches out to in order to perform an operation, like drawing or composing a panel, but instead, aim to become an immersive environment, which is active and granted with its own capacities.

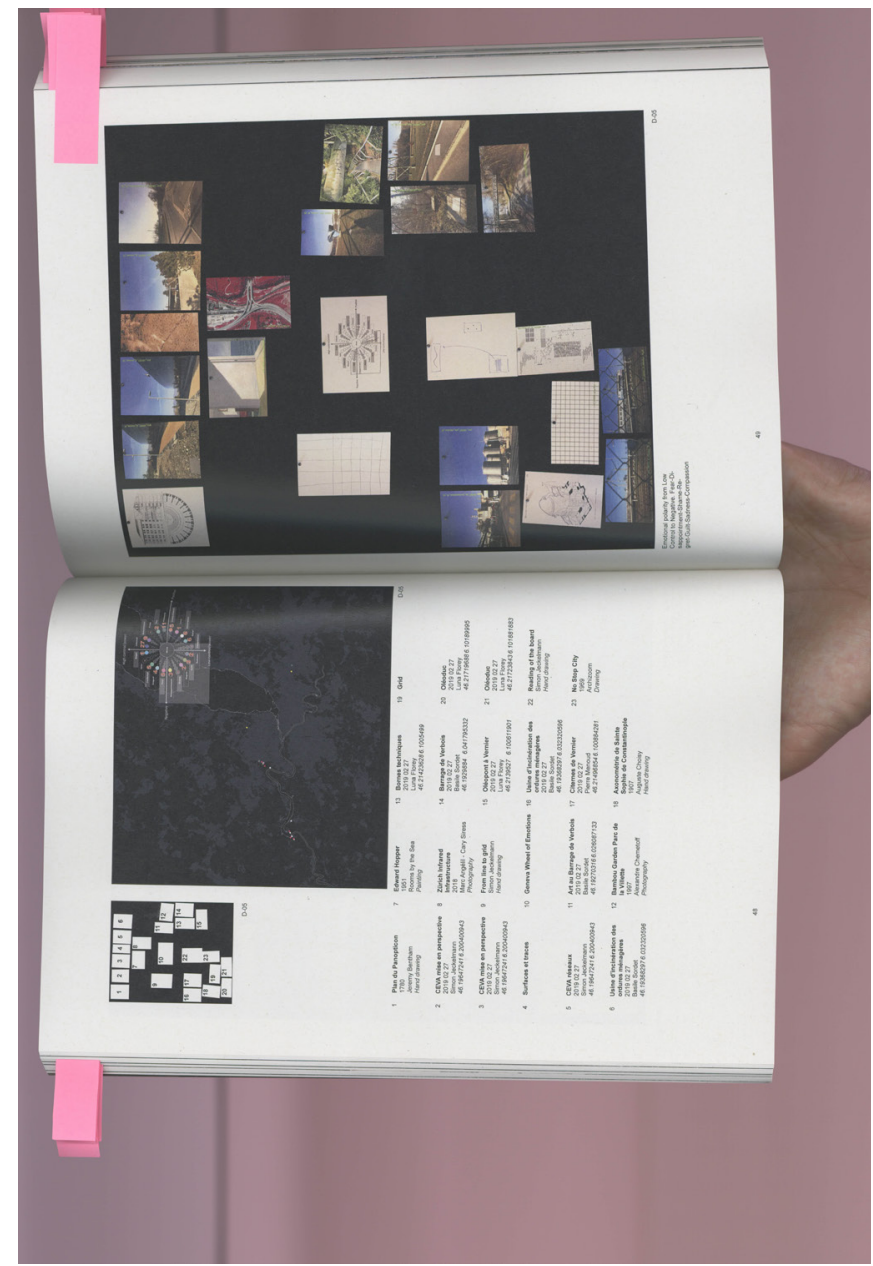

Figure 5. Board D_05. Emerged from the interactions between students around their emotional states and affective relationships with the spaces their visited during the previous survey.

The result of such a learning experience can only be uncertain, as it not possible anymore to anticipate optimal solutions to a "territorial diagnosis" through the application of a problem-solving mind-set.

This recognition of the agency of the participants, including non-human actors, is a central objective of the course, and is supported by an emphasis on the combined importance of a situated approach and of embodied knowledge. Such an objective requires thus valorising the sensorial beyond the anecdotal, as well as giving place to the sentient body to be a proper interface for environmental and social enquiry. An example of this is the use of a lexicon of emotion words which are applied to a subjective evaluation of the photographic material taken by the students (see figure 5, which is based on the use of affective vocabulary). By integrating them as values in the photographic database, a mesh of intersubjective affective vocabulary of their engagement with the territory is slowly composed and reworked. For that purpose, the Geneva Emotion Wheel ${ }^{6}$ is used as a tool for quick self evaluation. As the Wheel displays a predefined emotion vocabulary into a two dimensional scheme corresponding to the dimensions 
of valence and control, participants learn to capture the implicit appraisal contained by their emotional reactions to the different settings. By integrating this information into the shared database, we not only take this information seriously, but we make it re-visitable, re-workable, and subject to dialogue and conversation.

As participants interact and reconstitute the territory through iterative surveys, non-linear narrative threads emerge as the tool to navigate and reorder a veritable complex network of actors and information. This, in turn, allows for instantiations of intentional modes of reading that help those sensorial inputs become explicit and meaningful. During the third quarter of the course, participants proposed a micro-action, re-instantiating the thousand of liters of gases that were dispersed through the ground of the Northern industrial area under reconversion. Lying on the ground, hearing series of quantitative informations, the imagined matter is enacted in a interactable and explicit sensorium (figure 6). In this line, all participants composed intentionally new figurations of an intersubjective inhabited geography.

The consequences of this are threefold. On the one hand, there is the potentiality/gesturality/performativity of space, which can be read through synthetic patterns, rhythms and "appreciations or feelings" that cut across scales and types of phenomena. On the other hand, the acknowledgement of a situated and embodied dimension of knowledge gives way to an intentional reading/writing of our surrounding reality. The bodily (sensorial, sentient and reflecting) presence of all actors alter the object of study, creating a play field where intentions, memory, physical constraints and imagination are conjugated.

The effective extension of the Atlas does not only involve Sterelny's dimensions of incorporating the tools and trusting them as to them becoming transparent, but it also engages the territory itself. Our object of study is no longer "out there" but becomes what we do, just like our thoughts, and evolving dialogue are inscribed onto the territory. But this, of course, is of difficult assessment.

\section{MODEL AND NOT REPRESENTATION}

Traditionally, maps and images of a territory, in context of teaching architecture and city sciences are valued as visual representations; in this perspective, they are analysed and used exactly for what they entail, what they represent. Nevertheless, scholars from post-representational cartography? ${ }^{7}$, cognitive mapping and others ${ }^{8}$, in collaboration with art historians, recently claimed that it exists a major difference between a figure/figuration and a representation. Based on a twofold polarization, from distance/interchangeability to entrenchments, leading from a fixed to a generative interaction, this duality permits to categorize the relationships to an object according to its performativity as a model, open and fertile, acting upon the virtual, and a representation, keeping its distance with potentialities and subjectivities.

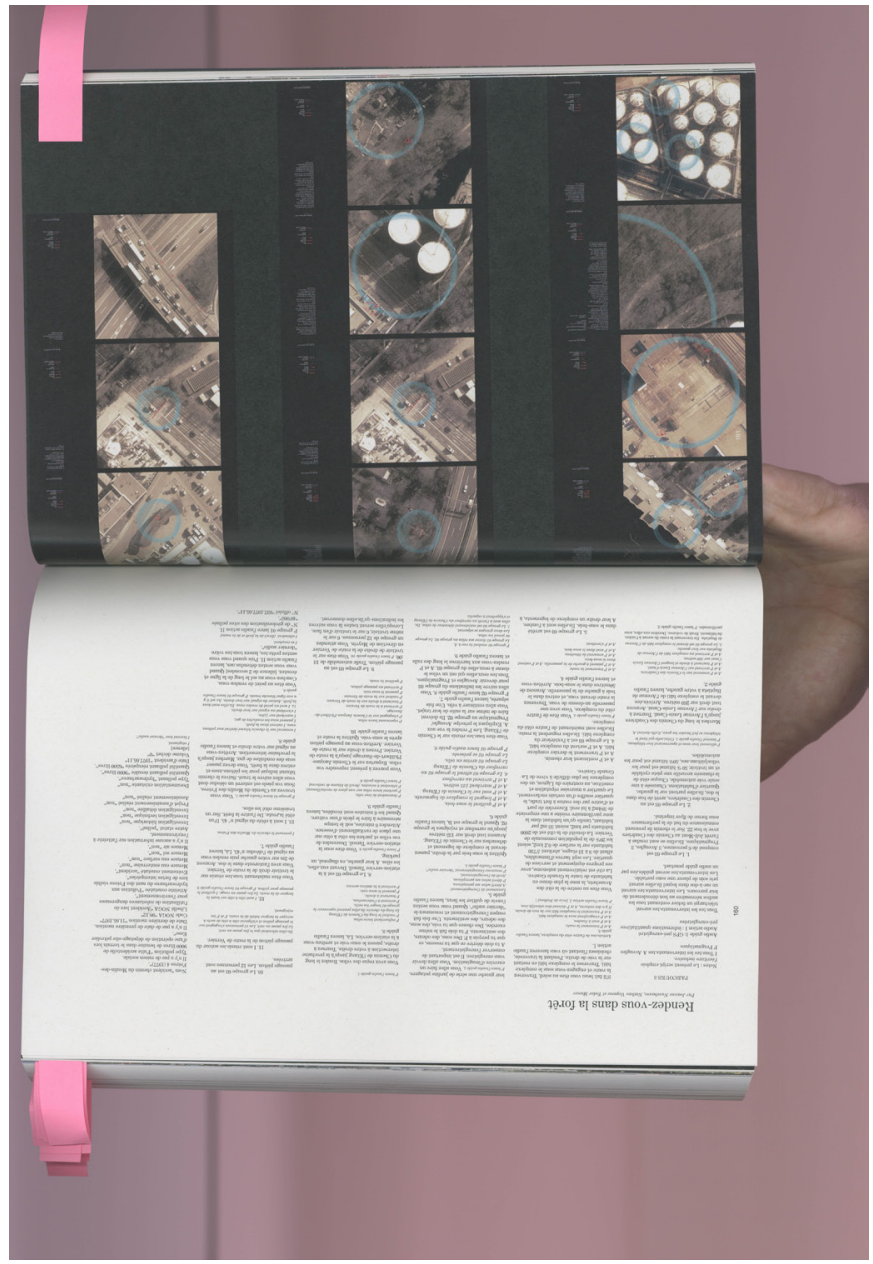

Figure 6. Script and Visual Scenario for the micro-action Rendez-vous dans la forêt, based on the exploration of under reconversion industrial area of Geneva.

The atlas has already been hypothesized as a performative device (Didi-Huberman 2011; Dora 2009)9. in art history, notably through the analysis of the Theatrum Orbis Terrarum of Abraham Ortellius, or the Warburg Mnemosyne Atlas. In this line, investigating the social and performative aspects, perhaps the most fruitful problematic and engendering aspect of the Atlas Poliphilo is its agential dimension. The Atlas does not work by gathering personal, anecdotal fixed representation of the territory. On the contrary, the iterative method of intentionally arranging different data, media and testimonies implies the construction and crafting of an open and intersubjective territorial model. This model is not given a priori, but built collectively through the enquiry and interaction with the territory and its actors. As an example, the second restitution was the occasion to relate every boards-that were already the product of collective discussions-with the others, and to create a temporary coherence to navigate in. As such, it is characterized by the objective to help us understand the territory of the Great Geneva Agglomeration but also to render us capable of acting upon it. 


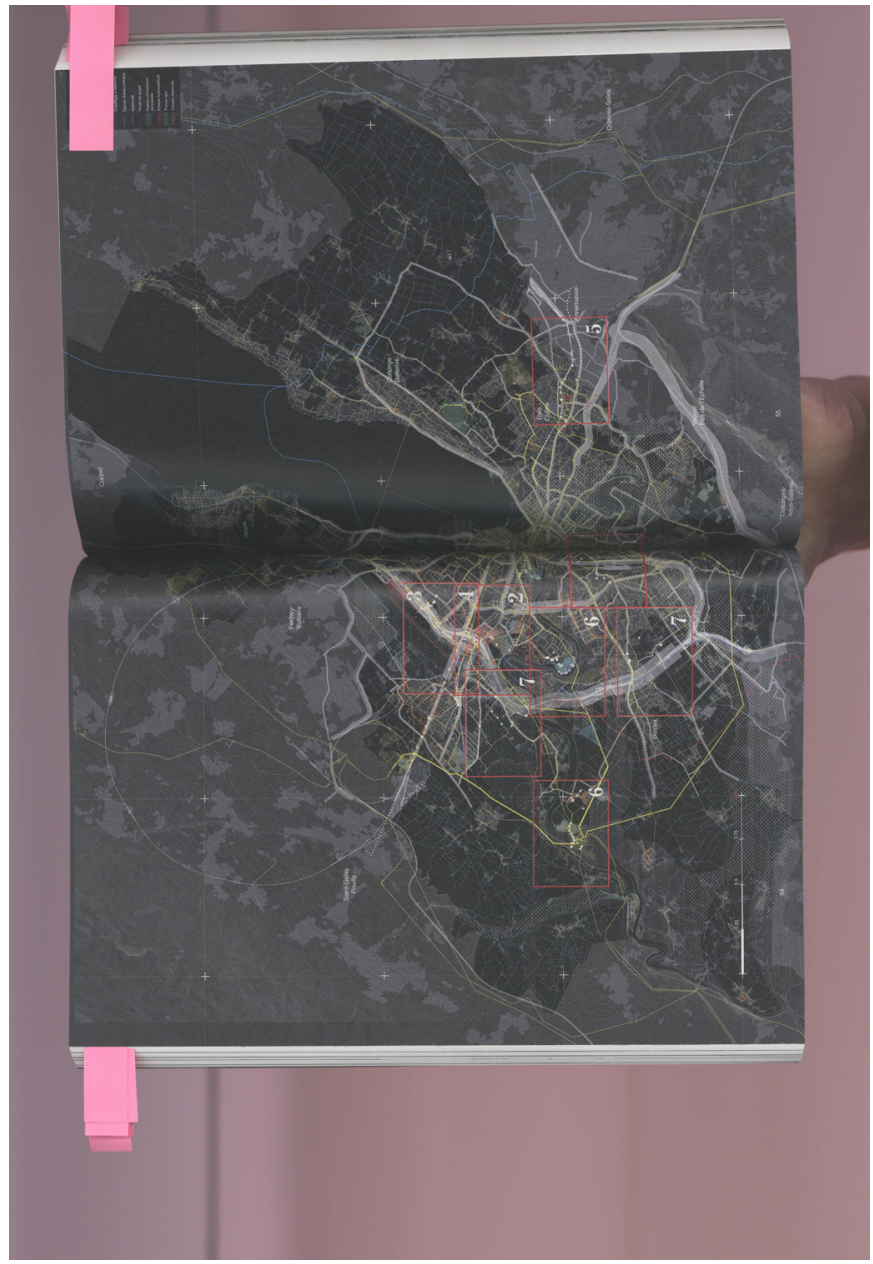

Figure 7. Final map gathering the informations produced by participants and the territories explored in relation with underground and emerged infrastructural network of the Great Geneva.

The spatial re-inscription of the collective and individual experience of each surveys in the studio, manipulating different media and emulating certain threads on the boards of the atlas, fosters a distance, a critical distance, between individuals, the collective and the territory. This distance is at the core of the territorial model agentiality, allowing for theoretical questioning, abstractions and their actualization in the space of the atlas. The participant is enacted as a researcher, allowing for the understanding and the re-articulation of the cultural patterns and the associated spatial affordances; simultaneously, the atlas is a technique fostering the potentialities and the capacities to act, radically increasing the virtual dimensions of the territory, which should ideally remain anchored in the sensory realm of matter. From the first surveys based on emotional integration-and by this means, an objectivized subjectivity, as discussed in the part two-to the performances enacted by the environmental scaffolding, the researchers/ participants are encouraged to use their bodies as a critical device; the iterative construction of threads through the model enacts dialogues and dances between the territory and the researcher/participants. As a performative threshold, the atlas makes matters vibrate; then, the vibrating matters tend to scaffold the researcher/participant behaviors and gestures, affording unexpected knowledge and engagement with virtualities and realities encountered in the territory. Lying and sitting, moving and interacting within a priori hostile environment, it fosters new relationships with spaces and environmental artifacts (see performance presented in figure 8).

One of the main direct consequences of this method is that this re-instantiation allows for a bifurcation on the trajectories followed by participants. As such, the process bears a reflectivity that prevents the linearity of reproduction. The territory, with both its physical dimension and its relational social and cultural tissue, is not taken as given, but as an active matter of enquiry, to be reconstituted and altered in the process. This reconstitution necessarily depends on the person, her affinities, her context and her intentions. The reflectivity entailed in the process thus not only concerns the territory modelled; it seeks to encompass the individual and embodied gestures and habits that are, in the same motion as the territorial representation immured in the high quality aerial photography of certain companies, drastically attained by the normalization of the cognitive capitalism ${ }^{10}$. Nevertheless, this necessary implication of intentionality/subjectivity and the complexity of the reflectivity was a problem unveiled at the moments of the collective restitution; as already evoked, external guests had difficulties, to read and understand the boards. Mostly, the board were commented and discussed as representations, upon what they entailed, and not upon their performativity and agency.

The Atlas proposes thus an instrument of both perception and action in the Simondonian sense ${ }^{11}$, allowing for active and constant reconfiguration as knowledge becomes concrete and shapes both the understanding of the surrounding environment, and the identity of the agents involved. The process of investigation, discussion and constitution of the boards is not just the individuation of the atlas in itself, but an individual and collective individuation of the researcher/ student and of the atlas, the individuation of their relationships. This implies the desire of a shift in the nature of the knowledge in the architectural teaching; knowledge as a relation or relational knowledge as the core of our disciplines, encouraging the inclusion of the individual embodied experiences, narratives and trajectories in the knowledge produced in architecture schools. This condition of enablers and individualizing differentiates the Atlas from other approaches to architectural education based on the transmission of "tools" that can be "applied" in order to find "solutions" to spatial or environmental "problems.' Within this frame we proposed to introduce a multifold instrument that fostered individual and heterogeneous approaches, always entailing means to communicate and relate with others, enabling the development of critical thinking, self-reflectivity and engagement with the citizenry. As a pedagogical experience, the atlas was an attempt to collectively share and integrate hunches, to experiment with them, and to create a generative model that gathers situated and embodied trajectories of the students and the agents of the territory. 


\section{CONCLUSION}

The ambitions for the elaboration of the theoretical, methodological and interactional dimensions of the course were very high, and the actual running of the course obviously provided us with additional challenges. To what extent students embrace this way of doing and thinking? Can they leave behind preconceived ideas about both their discipline and the territory? Could we consider their embodied experiences, narratives and trajectories as an understanding and describing of their own position as architects/researchers within the world?

All these questions seem to bring us to a more fluent definition and navigation through the concepts of teaching environment, professional reality, outside world or disciplines. The Atlas could potentially also be read as a performative threshold helping us to position ourselves within the liminal time and space between research and practice, between inside and outside a learning environment, that should not be limited to the one of the University. Instead, today's challenges and the effective role of the spatial production in those dynamics, that we want it or not, declare the necessity of a critical practice. This relies upon the fundamental dimension of engagement and the way it informs a professional agenda grounded on a strong ethical commitment with our shared future.

More concretely and as professionals or future ones, the Atlas asks us to consider time and space as active entities in the architectural process. Taking this claim seriously implies many shifts, for which the Atlas serves as first test ground. It brings us to reconsider tools of representation guiding most of the current urban production : the map alone should not be seen and used as equivalent of an ever changing sensible world. The repeated operation of abstraction leading to territorial decisions has a crucial impact on our minds and bodies, loosing or un-learning to trust our embodied knowledge and to connect it to territorial strategies. We nevertheless live in the concerned territory, and endure this split from within our knowing bodies.

Spaces and times of the territory must be heard in the architectural process, and it is thus not in a naive way that we claim that this could happen only through our knowing bodies and affects being taken seriously. This is why we are trying to explore ways to deal--as architects practising at the threshold--between daily and performed gestures, embodied experiences and their attached affects, images, drawings and physical realities of a territory. The process of the course shows how necessary it is to learn to dive in this complexity. In the professional context, this time is usually not given. But the time we loose here is the time we gain as engaged political community, taking care of a territory that supports us, and the many dimensions this implies the need to be taken into account. As such, the course invite to think further about our core knowledges as a capacity to deal with relations in space and materiality, and our practice as a way to establish the ground for new material realities, far from the current exploitation of resources we do not yet completely feel in our bodies.

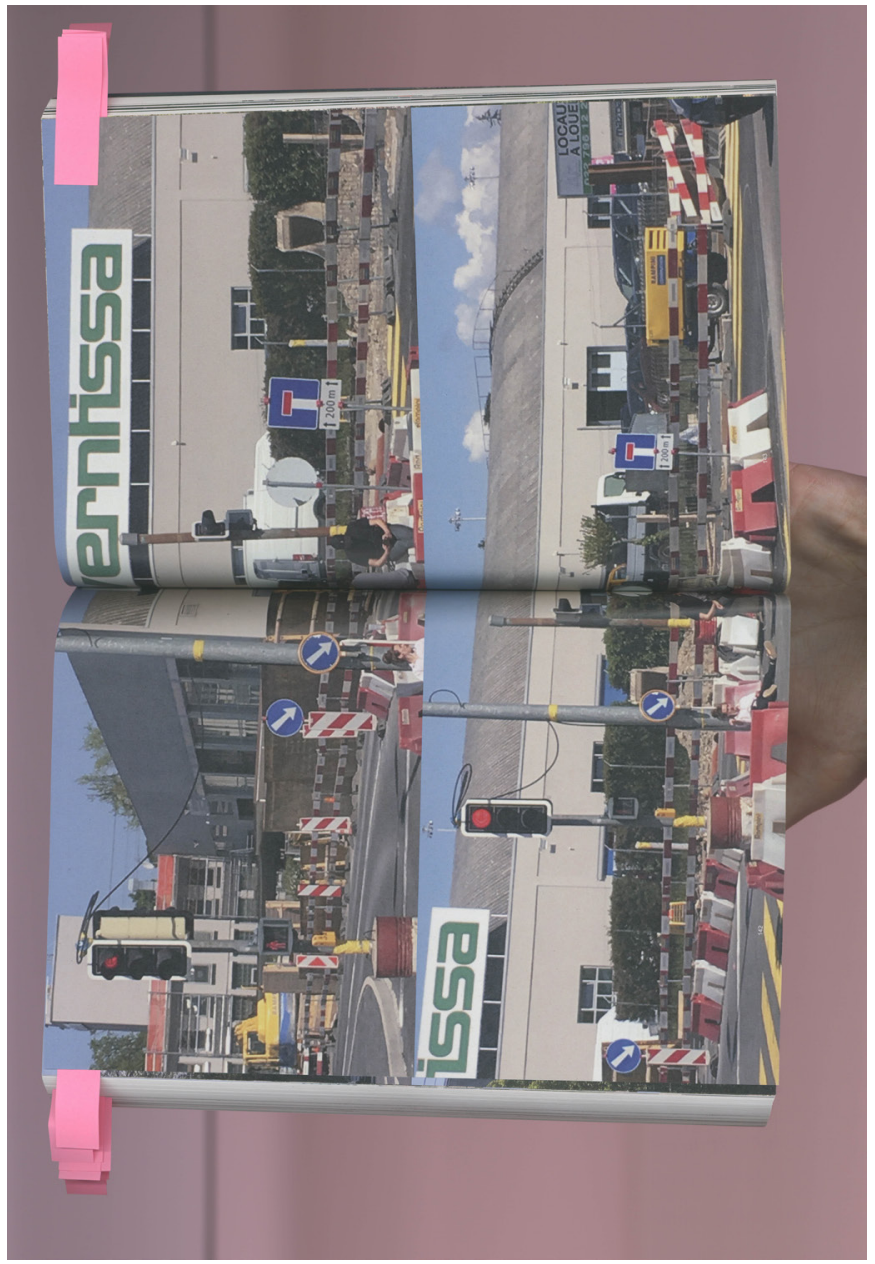

Figure 8. Photographies of the performance proposed by the participants during the last part of the course, questionning the hospitality and the affordances of industrial spaces in terms of use and relationships to the body.

\section{Notes}

1. Warburg, Aby Moritz, Joaquín Chamorro Mielke, Martin Warnke, Claudia Brinker, and Fernando Checa Cremades. Atlas Mnemosyne. Madrid: Akal, 2010.

2. Sterelny, Kim. "Minds: Extended or Scaffolded?" Phenomenology and the Cognitive Sciences 9, no. 4 (December 2010): 465-81. https://doi.org/10.1007/ s11097-010-9174-y.

3. See Wertsch, Voices of the Mind; Palincsar, 'Keeping the Metaphor of Scaffolding Fresh-A Response to C. Addison Stone's "The Metaphor of Scaffolding: Its Utility for the Field of Learning Disabilities"', Wertsch 1991 for scaffolding in Learning ; and Sterelny for cognitive scaffolding.

4. Or in the original sense of learning scaffolding, they "fade" See: Pea, 'The Social and Technological Dimensions of Scaffolding 
and Related Theoretical Concepts for Learning, Education, and Human Activity', 431.

5. Puntambekar and Hubscher, 'Tools for Scaffolding Students in a Complex Learning Environment'; Palincsar, 'Keeping the Metaphor of Scaffolding Fresh-A Response to C. Addison Stone's "The Metaphor of Scaffolding: Its Utility for the Field of Learning Disabilities"'.

6. Scherer, K. R. (2005). What are emotions? And how can they be measured? Social Science Information, 44(4), 693-727.

See also, Scherer, K.R., Shuman, V., Fontaine, J.R.J, \& Soriano, C. (2013). The GRID meets the Wheel: Assessing emotional feeling via self-report. In Johnny R.J. Fontaine, Klaus R. Scherer \& C. Soriano (Eds.), Components of Emotional Meaning: A sourcebook (pp. 281-298). Oxford: Oxford University Press.

7. Kitchin, Rob, and Martin Dodge. "Rethinking Maps." Progress in Human Geography 31, no. 3 (June 2007): 331-44. https:// doi.org/10.1177/0309132507077082.

8. Tversky, Barbara. "Cognitive Maps, Cognitive Collages, and Spatial Mental Models." In Spatial Information Theory A Theoretical Basis for GIS, edited by Andrew U. Frank and Irene Campari, 716:14-24. Berlin, Heidelberg: Springer Berlin Heidelberg, 1993. https://doi. org/10.1007/3-540-57207-4_2.

9. Dora, Veronica della. "Performative Atlases: Memory, Materiality, and (Co-)Authorship." Cartographica: The International Journal for Geographic Information and Geovisualization 44, no. 4 (December 2009): 240-55. https:// doi.org/10.3138/carto.44.4.240. and Didi-Huberman, Georges. L'oeil de l'histoire. 3: Atlas Ou Le Gai Savoir Inquiet. Paradoxe. Paris: Minuit, 2011.

10. Stiegler, Bernard. De la misère symbolique. Paris: Flammarion, 2013. and Jameson, Fredric. "Cognitive Mapping." In Marxism and the Interpretation of Culture. Communications and Culture. Basingstoke: Macmillan Education, 1988.

11. Simondon, Gilbert. On the Mode of Existence of Technical Objects. Minneapolis, MN: Univocal Pub, 2016. 